\title{
Pemanfaatan Media Online sebagai Sarana Promosi yang Efektif di SMK Nusa Bhakti Depok
}

\author{
Rudy Susanto*, Khoirul Umam, Indah Pangesti \\ Universitas Indraprasta PGRI \\ rudy.susanto19@gmail.com
}

\begin{abstract}
Abstrak
Kehadiran internet sebagai sarana atau media informasi online memberikan manfaat yang sangat besar bagi setiap aspek kehidupan yang ada. Baik di bidang pendidikan, sarana komunikasi, maupun dalam hal pengembangan usaha. Pemanfaatan media online memang menjadi pilihan tepat bagi para pelaku usaha untuk mengembangkan bisnis. Tanpa didukung strategi pemasaran yang tepat, usaha di bidang pendidikan tidak akan berkembang dengan baik, bahkan bisa mengalami kebangkrutan. Salah satu upaya yang dapat diterapkan untuk mendukung pengelolaan institusi pendidikan adalah dengan menerapkan media online terutama dalam hal promosi atau pemasaran. Hasil dari kegiatan ini menunjukkan bahwa dengan meningkatkan kompetensi dan keterampilan pihak manajemen dan guru-guru SMK Nusa Bhakti dalam menentukan strategi dan media online sebagai media promosi, maka kegiatan promosi sekolah dapat berjalan dengan baik, efektif dan efisien.
\end{abstract}

Kata Kunci: promosi, media online

\section{Utilization of Online Media as an Effective Promotion Facility at SMK Nusa Bhakti Depok}

\begin{abstract}
The presence of the internet as a means or media of online information provides enormous benefits for every aspect of life that exists. Both in the field of education, communication facilities, and in terms of business development. The use of online media is indeed the right choice for business people to develop their business. Without the support of the right marketing strategy, businesses in the field of education will not develop properly, and may even go bankrupt. One of the efforts that can be applied to support the management of educational institutions is by implementing online media, especially in terms of promotion or marketing. The results of this activity indicate that by increasing the competence and skills of the management and teachers of SMK Nusa Bhakti in determining strategies and online media as promotional media, school promotion activities can run well, effectively and efficiently.
\end{abstract}

Keywords: promotion, online media

\section{PENDAHULUAN}

Perkembangan informasi dan teknologi (IT) saat ini sangat masif. Pertumbuhannya yang sangat cepat membuat orang-orang mau tak mau harus mengejarnya agar tak jauh tertinggal. Percepatan teknologi dan informasi yang juga menyentuh dunia bisnis pada akhirnya membuat para pelaku pebisnis juga harus ikut meng-update dan menyesuaikan dirinya pada perkembangan IT tersebut. Salah satu hal yang harus disentuh oleh pebisnis era ini adalah teknologi internet. Bukan zamannya lagi kini pebisnis harus melakukan promosi dengan metode konvensional melalui media cetak seperti koran dan majalah atau media elektronik seperti radio, televisi. Ini karena telah hadir pilihan dan alternatif baru 
dalam kegiatan promosi bisnis para pengusaha yang sangat berpotensi besar mencapai konversi. Pilihan dan alternatif yang dimaksud adalah media online. Media Online yang memanfaatkan jaringan internet sekarang memang sudah bukan sesuatu yang asing lagi bagi para pebisnis. Dengan kemudahan, efisiensi dan efektivitas yang ditawarkannya, media online tentu saja menjadi sebuah solusi bagi mereka yang sulit untuk mendapatkan konversi bagi iklan yang dimilikinya dalam melakukan promosi online.

Kehadiran internet sebagai sarana atau media informasi online ternyata memberikan manfaat yang sangat besar bagi setiap aspek kehidupan yang ada. Baik dalam bidang pendidikan, sarana komunikasi tanpa batas, maupun dalam hal pengembangan usaha. Pemanfaatan media online memang menjadi pilihan tepat bagi para pelaku usaha untuk mengembangkan bisnis yang dijalankannya. Mudahnya akses internet saat ini, besarnya manfaat yang didapatkan, serta murahnya biaya yang dibutuhkan menjadi alasan utama bagi para pelaku usaha sebelum akhirnya mereka memilih media online sebagai solusi tepat untuk memperluas jangkauan bisnisnya. Hal ini dibuktikan dengan hasil survei Asosiasi Penyelenggara Jasa Internet Indonesia (APIJII) 2014, dari hasil survei ini fasilitas internet paling banyak digunakan untuk bisnis.

Banyaknya sumber informasi yang tersedia melalui media online atau internet, memberikan dukungan tersendiri bagi perkembangan bisnis termasuk dalam hal ini adalah institusi pendidikan. Dengan modal informasi yang ada pada media online, setidaknya bisa menciptakan ide-ide baru yang tentunya bermanfaat bagi kemajuan usaha.

SMK Nusa Bhakti yang terletak di Jalan H. Noir BSI Pengasinan, Sawangan Depok merupakan salah satu bentuk usaha bidang pendidikan yang memberikan kontribusi positif terhadap bidang pendidikan dan kualitas sumber daya manusia di Indonesia. Dalam upaya mempertahankan bisnis yang dijalankan, SMK Nusa Bhakti dituntut untuk mulai menerapkan berbagai macam strategi bisnis dalam upaya mengembangkan usaha untuk mencapai pangsa pasar yang lebih luas dan mendapatkan lebih banyak konsumen yang dalam hal ini adalah calon siswa baru yang mendaftar.

Tanpa didukung strategi pemasaran yang tepat, dapat dipastikan bahwa usaha bidang pendidikan tidak akan berkembang dengan baik, bahkan bisa mengalami kebangkrutan. Salah satu upaya yang dapat diterapkan untuk mendukung pengelolaan institusi pendidikan adalah dengan memanfaatkan media online dalam hal promosi atau pemasaran.

Pengabdian kepada masyarakat ini dilaksanakan untuk memberikan penjelasan dan pemahaman kepada pihak mitra mengenai pemanfaatan media online sebagai sarana promosi yang baik, tepat dan efektif untuk digunakan sebagai sarana promosi sekolah untuk meningkatkan pangsa pasar yaitu calon murid baru.

\section{METODE PELAKSANAAN}

Kegiatan pengabdian kepada masyarakat ini dilaksanakan pada Mei 2020 di SMK Nusa Bhakti Sawangan Depok. Adapun tahapan-tahapan dalam kegiatan pengabdian kepada masyarakat sebagai berikut: 
Vol. 1, No. 3,

November

2020

pp. $126-130$

e-ISSN:

2722-2004

Title

Utilization of

Online Media

as an

Effective

Promotion

Facility at

SMK Nusa

Bhakti Depok

Author

Rudy Susanto, Khoirul Umam, Indah Pangesti

\section{Tahap Awal}

Tim abdimas bertemu dengan pihak mitra untuk melakukan diskusi dalam rangka mengetahui permasalahan-permasalahan yang dihadapi oleh mitra, sehingga tim abdimas dapat memberikan solusi kepada mitra.

\section{Tahap Persiapan}

Tim abdimas mempersiapkan materi-materi yang berhubungan dengan media online yang akan dijelaskan kepada mitra, agar mitra mengerti dan memahami mengenai media online yang dapat digunakan sebagai sarana promosi.

\section{Tahap Pelaksanaan}

Pelaksanaan kegiatan pengabdian kepada masyarakat ini dilakukan melalui penyuluhan dengan cara sebagai berikut:

Penyampaian Materi

Tim abdimas menjelaskan materi-materi yang berhubungan dengan media online kepada mitra, seperti pentingnya media online; jenis-jenis media online; karakteristik media online yang tepat dan efektif sebagai sarana promosi; mengidentifikasi strategi bisnis yang tepat dengan media online sebagai sarana promosi.

Diskusi

Setelah materi penyuluhan dijelaskan oleh tim abdimas, kemudian dilakukan diskusi dengan para peserta. Diskusi ini dilakukan agar peserta lebih mengerti dan memahami materi yang sudah dijelaskan, selain itu diskusi ini juga untuk mengetahui kendala-kendala yang dihadapi oleh peserta dalam melakukan kegiatan promosi, agar tim abdimas dapat memberikan solusinya dalam rangka meningkatkan kompetensi dan keterampilan mitra untuk memanfaatkan media online sebagai sarana promosi yang efektif.

\section{Tahap Pelaporan}

Setelah pelaksanaan kegiatan pengabdian kepada masyarakat sudah selesai dilaksanakan, maka tim abdimas membuat laporan hasil dari kegiatan pengabdian kepada masyarakat tersebut.

\section{HASIL DAN PEMBAHASAN}

Dari hasil pembicaraan atau diskusi tim abdimas dengan mitra serta pengamatan, maka diperoleh beberapa permasalahan yang ada, yaitu:

1. Mitra belum dapat mengoptimalkan penggunaan media online sebagai sarana promosi sekolah.

2. Mitra mengalami kesulitan dalam menentukan media online yang baik dan tepat untuk media promosi sekolah.

Berdasarkan permasalahan tersebut, tim abdimas berusaha memberikan solusi, agar mitra dapat melakukan kegiatan promosi dengan baik, efektif dan efisien dalam rangka memperluas cakupan pangsa pasar atau konsumen, sehingga banyak masyarakat yang ingin bersekolah di tempat mitra. Solusi yang direkomendasikan oleh tim abdimas terhadap pihak mitra antara lain: 1) pihak 
mitra perlu memberikan pelatihan secara berkala kepada para guru dan staf sekolah untuk terampil dalam menggunakan dan mengoperasikan media online dan media sosial secara umum. 2) Pihak mitra perlu membuat program dan strategi promosi yang berbasis penggunaan media online dan media sosial yang akan dilaksanakan secara terpadu oleh guru dan karyawan sekolah dan konsisten. 3) Pihak mitra perlu melakukan pemetaan media online mana yang terbaik dan relevan sebagai sarana promosi sekolah dengan memperhitungkan efisiensi dan efektivitas promosi serta dampak yang dimunculkan dari penggunaan media tersebut. 4) Pihak mitra perlu melakukan analisis dampak dari penggunaan media online terpilih yang digunakan untuk promosi untuk mengukur efektivitas dan efisiensi penggunaannya melalui survey yang dilakukan kepada siswa yang mendaftar di sekolah tersebut. 5) Pihak mitra perlu merancang strategi promosi yang efektif untuk tahun ajaran baru berikutnya yang ditinjau dari hasil perolehan siswa dan efektivitas penggunaan media sosial dan online yang telah dilakukan sebelumnya

\section{SIMPULAN}

Dari kegiatan penyuluhan yang telah dilakukan oleh tim abdimas, pihak mitra banyak memperoleh manfaat seperti:

1. Pihak mitra mendapat tambahan ilmu mengenai strategi promosi dan media online.

2. Pihak mitra menjadi mengerti dan paham cara menentukan strategi promosi yang baik dan tepat untuk mempromosikan sekolah.

3. Pihak mitra menjadi mengerti dan paham cara menentukan media online yang baik dan tepat untuk mempromosikan sekolah.

\section{DAFTAR PUSTAKA}

Dharmesta, B. S. (2007). Azaz-Azaz, Marketing. Yogyakarta: Liberty Yogyakarta.

Hermawan, A. (2012). Komunikasi Pemasaran. Jakarta: Erlangga.

Kemendag. (2014). Panduan Optimalisasi Media Sosial untuk Kementrian Perdagangan RI. Jakarta: Ministri of Trade.

Kotler, P. \& Armstrong, G. (2008). Prinsip-Prinsip Pemasaran. Jakarta: Erlangga. Kotler, P. \& Keller, K. L. (2007). Manajemen Pemasaran. Jakarta: Indeks.

Lee, M. dan Johnson, C. (2007). Prinsip-prinsip Pokok Periklanan dalam Perspektif Global. Jakarta: Kencana Prenada Media Group.

Makmur, R. (2016). Bisnis Online. Bandung: Informatika Bandung.

McQuail, D. (2011). Teori Komunikasi Massa. Jakarta: Salemba Humanika.

Morissan. (2007). Periklanan Komunikasi Pemasaran Terpadu. Jakarta: Ramdina Prakarsa.

Nurudin. (2007). Pengantar Komunikasi Massa. Jakarta: PT Raja Grafindo Persada. Purwanto, D. (2014). Korespondensi Bisnis Profesional. Jakarta: Erlangga.

Shinta, A. (2011). Manajemen Pemasaran. Malang: Universitas Brawijaya Press (UB Press).

Siswanto, T. (2013). Optimalisasi Sosial Media sebagai Media Pemasaran Usaha Kecil Menengah. Jurnal Liquidity, Vol. 2, No 1. 80-86

Suharno, \& Sutarso, Y. (2015). Marketing in Practice. Samarinda: KP Books. 
KANGMAS: Karya Ilmiah Pengabdian Masyarakat, 1 (3), November 2020 - 130

http://journal.neolectura.com/index.php/Kangmas

Sunyoto, D. (2015). Strategi Pemasaran. Yogyakarta: CAPS (Center of Academic Publishing Service)

Vol. 1, No. 3,

November

2020

pp. $126-130$

e-ISSN:

2722-2004

Suryani, T. (2013). Perilaku Konsumen di Era Internet Implikasi Strategi pada Strategi pemasaran. Yogyakarta: Graha Ilmu.

Suyanto, (2007). Marketing Strategy Top Brand Indonesia. Yogyakarta: CV Andi Offset.

Tjiptono, F. (2008). Strategi Pemasaran Edisi Kedua. Yogyakarta: Penerbit Andi.

\section{Title}

Utilization of

Online Media

as an

Effective

Promotion

Facility at

SMK Nusa

Bhakti Depok

\section{Author}

Rudy Susanto, Khoirul Umam, Indah Pangesti 